\title{
Professional Issues
}

\section{Dating Violence Among College Students: Key Issues for College Counselors}

\author{
Christine E. Murray and Kerrie N. Kardatzke
}

\begin{abstract}
The authors present a review of literature examining dating violence among college students. They describe 6 key issues related to dating violence among college students that affect college counselors' work. These key issues relate to the incidence and prevalence of physical, sexual, and psychological violence in college students' dating relationships, risk factors and relationship dynamics associated with dating violence, and counseling issues-including related psychological symptoms and college students' reporting of dating violence to professionals.
\end{abstract}

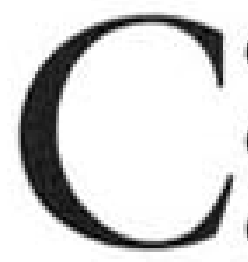

ollege counselors face many challenges when working with college students who have experienced dating violence in the past or are currently experiencing it. These challenges include using appropriate assessment strategies, helping clients examine the consequences of the violence, and treating comorbid presenting problems. Based on a review of the literature examining college student dating violence, key issues are highlighted for college counselors to consider when they work with students whose lives have been touched by dating violence. We begin by presenting definitions of dating violence. We then describe six key issues and their implications for college counselors. The final section identifies future directions for research and practice.

Definitions of dating and dating violence vary within the existing research. Therefore, we begin by clarifying our definitions of these terms. We define dating as a relationship in which two individuals share an emotional, romantic, and/or sexual connection beyond a friendship, but they are not married, engaged, or in a similarly committed relationship (i.e., have not participated in a lifelong commitment ceremony). This definition is inclusive of heterosexual and same-sex dating couples, although the majority of research described in the literature was conducted with heterosexual couples. Like Lewis and Fremouw (2000), we have adopted Sugarman and Hotaling's (1989) definition of dating violence and dating abuse as "the use or threat of physical force or restraint carried out with the intent of causing pain or injury to another" (p. 5) within a dating relationship. We also include sexual (Carr \& VanDeusen, 2002) and psychological abuse (Carr \& VanDeusen, 2002; Charkow \& Nelson, 2000) as components of dating violence. Examples of sexual abuse in violent dating relationships include forced or coerced sexual activity (Aosved \& Long, 2005), and examples of psychological abuse include dominating behaviors, verbal denigration, and social isolation (Murphy \& Hoover, 1999). Physical,

Christine E.Murray and Kerrie N. Kardatzke, Department of Counseling and Educational Development, The University of North Carolina at Greensboro. Correspondence concerning this article should be addressed to Christine E. Murray, PO Box 26170, Greensboro, NC 27402 (e-mail: cemurray@uncg.edu).

(C) 2007 by the American Counseling Association. All rights reserved.

Journal of College Counseling - Spring 2007 • Volume 10 
sexual, and psychological violence often co-occur in abusive dating relationships (Lewis, Travea, \& Fremouw, 2002). We consider a dating relationship to be violent if one or more forms of violence are present. We use the terms dating violence and dating abuse interchangeably throughout this article.

\section{Key Issues for College Counselors}

We reviewed over 60 articles pertaining to dating violence among college students and identified major themes relevant to college counseling. We present six key issues intended to inform the practice of college counseling with students affected by dating violence. Because of space limitations, we cite only the most relevant articles in this section. The complete list of articles reviewed for this study is available from the first author.

Key issue 1: Physical and sexual dating violence are common on college campuses. Perhaps reflecting the assorted definitions used by researchers, estimates about the rates of physical and sexual dating violence vary widely. One of the earliest studies on college student dating violence (Makepeace, 1981) showed that approximately $20 \%$ of college students had experienced at least one incident of physical dating violence. Since that time, rates of physical dating violence among college students have ranged from $16.7 \%$ (Makepeace, 1986) to $48 \%$ (Amar \& Gennaro, 2005). A recent study by Straus (2004) drew similar conclusions regarding rates of physical dating violence using data from an international survey of college students at 31 universities in 16 countries. At the median university in this study, $29 \%$ of students reported that they had been physically violent toward a dating partner within the past year, and the range of rates was from $17 \%$ to $45 \%$. These rates are significant in that "even at the university with the lowest rate, $17 \%$ of the students had physically assaulted a dating partner in the previous 12 months" (Straus, 2004, p. 799).

The rates of sexual dating violence are also high. Reporting on a national survey of Canadian college students, DeKeseredy and Kelly (1993) found that $27.8 \%$ of female students reported that they had been sexually abused within the past year. Similarly, Nicholson et al. (1998) demonstrated that $35.5 \%$ of college women had experienced unwanted sexual activity. Nicholson et al. also found that $11.3 \%$ of men reported unwanted sexual activity. These findings suggest that approximately 1 in 3 college women and 1 in 10 college men may be victims of sexual dating violence.

Researchers have published mixed findings regarding perpetration of gender and dating violence (Lewis \& Fremouw, 2000), with some studies reporting that men and women commit violent acts at similar rates (Makepeace, 1986; Straus, 2004) and other studies showing that women have higher rates of dating violence perpetration than do men (Foo \& Margolin, 1995; Hendy et al., 2003; Marcus \& Swett, 2002). Sugarman and Hotaling (1989) concluded that dating violence seems to be "largely mutual" (p. 10), with high correlations between being a victim and being a perpetrator. However, men and women may perpetrate dating violence behaviors for different reasons and with different outcomes. For example, Makepeace (1986) found that college women who perpetrated dating violence reported that their violence was performed in self-defense more often 
than did men, who were most likely to report that their motives were related to uncontrollable anger or a desire to intimidate their partners. In addition, dating violence perpetrated by men tended to be more severe and more likely to result in injury as compared with violence perpetrated by women (Lewis \& Fremouw, 2000; Makepeace, 1986; Marcus \& Swett, 2002).

Reported rates of dating violence should be considered to be underestimated because of the number of issues that complicate the reporting and measurement of dating violence (DeKeseredy \& Kelly, 1993). The accuracy of victims' and perpetrators' reports of violence in dating relationships is confounded by social desirability (Sugarman \& Hotaling, 1997) and subjective definitions of the terms abuse and violence (Neufeld, McNamara, \& Ertl, 1999). Thus, although the statistics reported in this section appear high, the rates are likely to be even higher, rendering dating violence a common occurrence among college students (DeKeseredy \& Kelly, 1993).

Key issue 2: Psychological dating violence appears to be more common than physical and sexual dating violence. DeKeseredy and Kelly (1993) found that $79.1 \%$ of Canadian female college students had been psychologically abused within the past year. Neufeld et al. (1999) found similarly high rates in their study of 623 college women; within the previous 6 months, over $75 \%$ of their study's participants had experienced psychological abuse. In another study, White and Koss (1991) surveyed a national sample of 4,707 college students. Of the male participants, $81 \%$ had perpetrated and $81 \%$ had been a victim of psychological dating violence; of the women, $87 \%$ had perpetrated and $88 \%$ had been a victim of psychological dating violence. Rates of perpetrating or being a victim of physical violence were lower, ranging from $32 \%$ to $39 \%$ for both men and women. Together, these studies indicate that psychological abuse is more common than physical or sexual dating violence for college students.

There is considerably less research that has examined psychological abuse in dating relationships as compared with physical and sexual violence (Murphy \& Hoover, 1999). The existing research indicates that psychological abuse often co-occurs with sexual (Aosved \& Long, 2005) and physical aggression (Murphy \& Hoover, 1999). Even when not combined with other forms of violence, psychological abuse is likely to be detrimental to the mental health of college students. As Neufeld et al. (1999) wrote, "the negative effects of psychological abuse on the victim's self-esteem and recovery far outweigh the immediate effects of physical violence" (p. 126).

Key issue 3: Researchers bave identified individual risk factors for college student dating violence. Individual risk factors fall under certain categories, including family history, peer influences, personal beliefs, alcohol use and abuse, and psychological factors. These categories are consistent with the risk categories outlined by Sugarman and Hotaling (1989) almost 2 decades ago. Although the factors studied remain consistent, research findings are often inconclusive or contradictory (Lewis \& Fremouw, 2000), suggesting that the influence of these factors may depend on a variety of undetermined mediating or moderating variables.

Family history factors include witnessing interparental violence (Carr \& VanDeusen, 2002; Coker, Smith, McKeown, \& King, 2000; Foo \& Margolin, 
1995; Hendy et al., 2003) and having a history of childhood abuse (Hendy et al., 2003; Pipes \& LeBov-Keeler, 1997). The influence of peer group norms also seems to have an impact on the likelihood of experiencing dating violence (Capaldi, Dishion, Stoolmiller, \& Yoerger, 2001; DeKeseredy, Schwartz, \& Alvi, 2000). Both parental and peer influences on the experience of college dating violence can be understood from a social learning perspective (Capaldi et al., 2001; Hendy et al., 2003), which holds that relationship behaviors are learned by observing the actions of others who are important in one's life.

Beliefs and attitudes about dating relationships have also been connected to college dating violence (Carr \& VanDeusen, 2002; Follingstad, Bradley, Laughlin, \& Burke, 1999; Pipes \& LeBov-Keeler, 1997). Carr and VanDeusen found that hostile attitudes and acceptance of violence against women was a significant predictor of sexual aggression in relationships. Follingstad et al. (1999) found that perpetrators of dating violence were more likely to have irrational behaviors and beliefs. The findings of Pipes and LeBov-Keeler supported the false consensus effect, which suggests that people in abusive relationships overestimate the number of others who are in abusive relationships. These authors proposed that "being abused leads to the belief that most other women are abused, which in turn leads to more toleration for the abuse" (Pipes \& LeBov-Keeler, p. 588). These aforementioned studies suggest that beliefs about acceptable behavior in dating relationships can have a powerful impact on perpetrators and victims of dating violence.

The use and abuse of alcohol has been linked to dating violence (Lewis \& Fremouw, 2000). Follingstad et al. (1999) found that violent men demonstrated more problems with alcohol use than did nonviolent men. In a similar comparison among nonviolent, psychologically violent, and physically violent college men who were dating, physically violent men reported more problems with alcohol than did men in the other two groups (Lundeberg, Stith, Penn, \& Ward, 2004). Alcohol use also seems to be prevalent in sexual violence incidents. Nicholson et al. (1998) found that alcohol was involved in over $80 \%$ of the unwanted sexual activity and in $50 \%$ to $62 \%$ of the rapes reported by both men and women.

Numerous psychological and emotional factors seem to be linked to dating violence, including low self-esteem (Clements, Ogle, \& Sabourin, 2005; Lewis \& Fremouw, 2000), antisocial behavior (Capaldi et al., 2001), high levels of jealousy (Follingstad et al., 1999; Lloyd \& Emory, 2000), angry temperament (Follingstad, Bradley, Helff, \& Laughlin, 2002), and anxious attachment (Follingstad et al., 2002). In addition to these psychological factors, increased daily stress (Follingstad et al., 1999) and lack of social support (Lewis \& Fremouw, 2000) have been shown to relate significantly to college dating violence.

Key issue 4: Certain relationship dynamics may make it more likely for dating violence to occur within college students' relationships, particularly dynamics related to power and control. Couple dynamics such as relationship dependency (Charkow \& Nelson, 2000), communication patterns (Mahlstedt \& Welsh, 2005), duration and seriousness of relationship, and intimacy factors (Marcus \& Swett, 2002) have been linked to college dating violence. Charkow and Nelson reported that female college students involved in a relationship char- 
acterized by "infatuation, obsessive love, relationship dependency, or addictive love" (p. 18) are more likely to be both victims and perpetrators of violence in the relationship. Dating violence has also been shown to increase with the duration and seriousness of the relationship (Marcus \& Swett, 2002), possibly related to increased emotional dependency on the partner, feelings of entrapment in the relationship, and increased expression of negativity.

Smith and Donnelly (2001) suggested that the violent relationship processes found in marital domestic violence (e.g., power issues and the cycle of tension building, violence, and reconciliation) also occur in dating relationships. Power issues in violent relationships involve an abusive partner's use of tactics to manage, dictate, and limit the other partner's behaviors (Jacobson \& Gottman, 1998). Examples of these tactics include demonstrating extreme jealousy and possessiveness and using degrading language to elevate one's power status. The available research suggests that power dynamics are common in violent dating relationships. For example, Lloyd and Emery (2000) conducted in-depth interviews with 40 college women who had been physically and/or sexually abused while in a dating relationship. These women commonly mentioned that jealousy and control issues were closely related to the physically and sexually violent incidents in their relationships. In addition, college students in general campus populations recognized the role of power and control in violent relationships (Mahlstedt \& Welsh, 2005).

Other relationship dynamics, such as empathy and intimacy, may serve as protective or buffering factors against dating violence. Marcus and Swett (2002) found that the following three elements of intimacy were associated with lower levels of violence in the relationship: "positive affective tone, listening and understanding, and self-disclosure" (p. 576).

Key issue 5: College students who experience dating violence are more likely to tell friends about their experiences than they are to report the violence to counselors and/or law enforcement officials. The secrecy surrounding dating violence hinders effective treatment and prevention (Smith \& Donnelly, 2001). Individuals who have been abused in dating relationships may not tell others for various reasons (Lloyd \& Emery, 2000), which include shame, isolation, fear of rejection, and fear of retaliation. For these reasons, college students who have been victims or perpetrators of dating violence are often unlikely to report their experiences to anyone, and especially to professionals such as counselors and law enforcement officers.

Amar and Gennaro (2005) found that approximately half of female college students who had experienced dating violence had told anyone about the violence. Those who did tell were most likely to have told friends (50\%), and only about $6 \%$ had told a counselor. A study by Mitchell and Lacour (2001) suggested that certain background characteristics of college counselors influence their clients' willingness to report physical and sexual violence. For example, clients were more likely to disclose physical abuse to female counselors and to staff counselors with less prominent position titles in the organization.

Key issue 6: Violence may be overshadowed by clients' other presenting problems in college counseling centers. Given the high rates of dating violence among college student populations, college counselors are likely to work regularly 
with students affected by dating violence. However, because students may not report these experiences, it is important for college counselors to be aware of common presenting problems that co-occur with dating violence.

Research studies indicate that dating violence increases the likelihood that a college student will demonstrate psychological symptoms (Amar \& Gennaro, 2005; Clements et al., 2005; Coffey, Leitenberg, Henning, Bennett, \& Jankowski, 1996). Both Amar and Gennaro and Coffey et al. demonstrated that female college students who were victims of dating violence demonstrated greater psychological distress and more mental health symptoms as compared with female college students who had not been victims of dating violence. In addition, Clements et al. found that college students who experienced relationship abuse reported higher levels of dysphoria and hopelessness as compared with college students reporting no relationship violence. In light of their findings, Clements et al. concluded that "both men and women who experience abusive behavior should be considered at high risk for the development of psychological symptoms" (p. 1070).

Two other presenting problems for which a college student might seek counseling have been linked to dating violence. First, both victims and perpetrators of dating violence may demonstrate decreased self-esteem (Clements et al., 2005; Lewis et al., 2002; Pipes \& LeBov-Keeler, 1997). Second, unhealthy weight loss behaviors have been associated with dating violence. Ferrier, Martens, and Cimini (2005) examined the relationship between college dating violence and unhealthy weight loss behaviors in women, and they found that participants who reported involvement in abusive relationships demonstrated an increased use of unhealthy weight loss behaviors. These researchers suggested that unhealthy weight loss behaviors may serve as a coping mechanism for some college women who are involved in violent relationships.

\section{Future Directions for Research and Practice}

Research has demonstrated the significant scope of the problem of dating violence among college students. College counselors remain on the front lines of the movement to prevent, identify, and treat dating violence among college students. Although progress has been made in these areas, much work remains to be done (Schewe, 2002). Therefore, we conclude this article with some future directions for research and practice specific to the needs of college counselors.

\section{Future Directions for Research}

Much more research is needed before counseling researchers and practitioners can fully understand the dynamics, risk factors, treatment, and prevention of dating violence among college students. Previously, scholars have identified several gaps in the literature. DeKeseredy et al. (2000) recommended that research is needed to examine the reasons college men are often hesitant to participate in programs that counter dating violence. In addition, Lewis and Fremouw (2000) suggested that researchers should use longitudinal and experimental designs in their study of college student dating violence. Beyond these 
recommendations, our review of the literature indicated that increased research efforts are needed (a) to identify effective assessment strategies, (b) to determine counseling strategies that increase the likelihood that clients who have experienced dating violence will report those experiences, and (c) to identify effective interventions to treat co-occurring dating violence and psychological symptoms.

\section{Future Directions for Practice}

Very few evaluations of dating violence prevention programs are published in the scholarly literature (Avery-Leaf \& Cascardi, 2002). Likewise, our literature review did not reveal any published studies evaluating treatment strategies for dating violence among college students. Thus, recommendations that appear in the literature should be considered tentative. On the basis of the existing research, we provide the following provisional guidelines to assist college counselors in their work with college students who are affected by dating violence: (a) conduct a thorough assessment related to dating violence experiences with all clients, (b) make safety a primary goal of treatment, (c) explore both positive and negative relationship dynamics-including power and control issues - within college students' dating relationships, (d) develop strategies for working with friends of victims of dating violence, (e) conduct prevention work as a component of efforts to address dating violence, and (f) be sensitive to counselor characteristics that may influence students' reporting of dating violence experiences.

Assessment. College counselors should assess clients' involvement in violent dating relationships. Because of the links between dating violence and other common presenting problems (Amar \& Gennaro, 2005; Clements et al., 2005; Coffey et al., 1996), we urge college counselors to assess all college students who seek counseling services for dating violence. Although clients often present with these problems with no history of dating violence, this cautious approach is likely to increase the probability that dating violence will be recognized and treated. The dating violence risk factors described previously are not comprehensive or conclusive (Lewis \& Fremouw, 2000), but they are warning signs that may indicate a need for counselors to assess for college dating violence. In particular, counselors should give careful consideration to assessment when working with students who demonstrate multiple risk factors.

Counselors may wish to use existing assessment tools as part of their assessment for dating violence. Commonly used measures include the Conflict Tactics Scale (Straus, Hamby, Boney-McCoy, \& Sugarman, 1996) and the Sexual Experiences Survey (Koss \& Oros, 1982). In addition to existing measures, counselors may add items to their intake assessment forms that assess for dating violence (e.g., "In a dating relationship, has a partner ever done anything to hurt you physically, emotionally, or sexually?" "Have you ever been physically violent toward someone you were dating?" "Have you ever pressured your dating partner to be sexual with you?" or "Have you ever said anything to hurt your partner, such as calling her or him a name or criticizing the way he or she does things?"). Counselors may need to provide specific examples 
of abusive behaviors to their clients throughout the assessment process to clarify for the client the definition of abusive behaviors. Our clinical experience has demonstrated that during formal assessments, clients occasionally say that they have not been "abused" but later acknowledge that a partner has hit them, kicked them, or called them names.

Safety issues. Safety of the client, other students, and the counselor must be a primary consideration when counseling clients affected by dating violence. Counseling centers should establish treatment protocols to use when working with clients who have experienced dating violence, which may include developing safety plans and notifying law enforcement officials if a student is in immediate danger. Neufeld et al. (1999) stressed the importance of counselors to discuss risk factors and early warning signs of violence with students. DeKeseredy et al. (2000) suggested that many existing programs have not been effective because of their focus on training potential victims to monitor and change the behavior of abusive partners and also because of the belief of many abusive partners that they will not be punished. Therefore, college counselors can work with clients who have perpetrated dating violence to help them to arrive at the point of accepting personal responsibility for stopping their violent behaviors. These efforts can help students recognize early warning signs of potentially abusive situations, thereby increasing client and campus safety.

Relationship dynamics. Counselors may find it helpful to explore both positive and negative relationship dynamics when working with clients who are affected by dating violence. An exploration of positive relationship characteristics can help clients identify protective factors that may reduce the likelihood of experiencing dating violence. Working with clients to build on the existing strengths of their relationships can further support these clients in developing healthy, nonviolent relationships. Training in relationship skills-such as communication and conflict management-provides an additional resource for students' relationships.

In light of the important role of power and control dynamics in violent relationships, college counselors should incorporate a focus on power and control in their work related to dating violence (Mahlstedt \& Welsh, 2005). Counselors can explore these issues using the Power and Control Wheels (Domestic Abuse Intervention Project, 2006). These wheels depict abusive and nonabusive relationship behaviors using a helpful visual schema. In addition, the use of empowering language (e.g., helping victims to view themselves as survivors) can be especially influential in helping clients feel capable of developing positive dating relationships in the future.

Working with friends of dating violence victims. An implication of the greater likelihood that victims of dating violence will tell friends rather than a professional about their experiences is that college counselors may work with clients who are experiencing distress related to knowledge that a friend is experiencing dating violence. These clients may express uncertainty as to how to respond or help their friends to leave the violent dating relationship. College counselors who work with these clients can assist them in practicing supportive responses, developing knowledge about dating violence, and identifying campus and community resources-such as shelters, hotlines, and legal assistance (West \& Wandrei, 2002). 
Prevention work. Although some scholars (Lewis \& Fremouw, 2000; Lewis et al., 2002) have suggested that it is premature to develop dating violence prevention interventions because of the inconclusive nature of existing empirical research in the area, we agree with others (Carr \& VanDeusen, 2002; Roark, 1987) who have proposed that preventive interventions are critically needed and very feasible. Nicholson et al. (1998) stressed the importance of interventions that aim to change campus cultures to make them less tolerant of violence. They stated, "Solutions will require not only effective interventions, but changes in campus traditions, norms, and culture" (Nicholson et al., 1998, p. 49).

Scholars have proposed guidelines for programs for prevention of college student dating violence. These recommendations include (a) increasing students' self-esteem (Roark, 1987; Rosen \& Bezold, 1996), (b) training program implementers and professionals who work with students (Avery-Leaf \& Cascardi, 2002; Smith \& Donnelly, 2001), (c) offering follow-up booster sessions (Avery-Leaf \& Cascardi, 2002), (d) using a peer counseling component (Avery-Leaf \& Cascardi, 2002; Smith \& Donnelly, 2001), (e) focusing on anger management skills (Lundeberg et al., 2004; Roark, 1987), (f) addressing alcohol-related issues (Lundeberg et al., 2004; Roark, 1987), (g) discussing power and control issues (Mahlstedt \& Welsh, 2005), and (h) increasing students' knowledge about dating violence (Rosen \& Bezold, 1996). College counselors can partner with other campus organizations - such as residence life and student health care organizations - to disseminate dating violence prevention programming.

Counselor characteristics. The findings regarding the influence of counselor characteristics on client disclosure of dating violence experiences (Mitchell \& Lacour, 2001) are in need of further study. However, these findings suggest that certain counselor characteristics may make it more likely that a client who has experienced dating violence will feel comfortable to report that experience to a staff member in a college counseling center. Therefore, counselors should be sensitive to the fact that their personal background characteristics can influence their clients' comfort levels in reporting dating violence to them. We also propose (a) that clients will benefit from being given the opportunity to state their preferences for working with a counselor of a particular background (when practical, given the resources of a counseling center) and (b) that a counselor who suspects that a client is not reporting dating violence experiences should offer to assist that client in seeking the services of another counselor with whom he or she would be more comfortable.

\section{Conclusion}

Dating violence is an unfortunately common experience for many college students today. We urge counselors not to overlook the resilience of clients who have been victims of dating violence (Lloyd \& Emery, 2000). Clients who disclose dating violence should be validated for the courage it took to report those experiences despite the many pressures they likely faced to keep the violence a secret. Treatment strategies that mobilize clients' resources, empower clients to make decisions, and develop clients' self-esteem can help 
clients overcome their histories of dating violence and move toward healthy relationships. Therefore, college counselors are in a prime position to help college students who have been involved in violent dating relationships to develop new, more positive ways of relating to their intimate partners.

\section{References}

Amar, A. F., \& Gennaro, S. (2005). Dating violence in college women: Associated physical injury, healthcare usage, and mental health symptoms. Nursing Research, 54, 235-242.

Aosved, A. C., \& Long, P. J. (2005). College women's experiences of psychological maltreatment and sexual assault. Violence and Victims, 20, 577-587.

Avery-Leaf, S., \& Cascardi, M. (2002). Dating violence education: Prevention and early intervention strategies. In P. A. Schewe (Ed.), Preventing violence in relationships: Interventions across the life span (pp. 79-105). Washington, DC: American Psychological Association.

Capaldi, D. M., Dishion, T. J., Stoolmiller, M., \& Yoerger, K. (2001). Aggression toward female partners by at-risk young men: The contribution of male adolescent friendships. Developmental Psychology, 37, 61-73.

Carr, J. L., \& VanDeusen, K. M. (2002). The relationship between family of origin violence and dating violence in college men. Journal of Interpersonal Violence, 17, 630-646.

Charkow, W. B., \& Nelson, E. S. (2000). Relationship dependency, dating violence, and scripts of female college students. Journal of College Counseling, 3, 17-28.

Clements, C., Ogle, R., \& Sabourin, C. (2005). Perceived control and emotional status in abusive college student relationships: An exploration of gender differences. Journal of Interpersonal Violence, 20, 1058-1077.

Coffey, P., Leitenberg, H., Henning, K., Bennett, R. T., \& Jankowski, M. K. (1996). Dating violence: The association between methods of coping and women's psychological adjustment. Violence and Victims, 11, 227-238.

Coker, A. L., Smith, P. H., McKeown, R. E., \& King, M. J. (2000). Frequency and correlates of intimate partner violence by type: Physical, sexual, and psychological battering. American Journal of Public Health, 90, 553-559.

DeKeseredy, W. S., \& Kelly, K. (1993). The incidence and prevalence of woman abuse in Canadian university and college dating relationships. Canadian Journal of Sociology, 18, 137-159.

DeKeseredy, W. S., Schwartz, M. D., \& Alvi, S. (2000). The role of profeminist men in dealing with women abuse on the Canadian college campus. Violence Against Women, 6, 918-935.

Domestic Abuse Intervention Project. (2006). Domestic Abuse Intervention Project: Communitybased intervention. Retrieved July 11, 2006 from http://www.duluth-model.org/wheels.html

Ferrier, A. G., Martens, M. P., \& Cimini, M. D. (2005). The relationship between physical, sexual, and emotional abuse and unhealthy weight loss behaviors. Journal of College Counseling, 8, 118-126.

Follingstad, D. R., Bradley, R. G., Helff, C. M., \& Laughlin, J. E. (2002). A model for predicting dating violence: Anxious attachment, angry temperament, and need for relationship control. Violence and Victims, 17, 35-47.

Follingstad, D. R., Bradley, R. G., Laughlin, J. E., \& Burke, L. (1999). Risk factors and correlates of dating violence: The relevance of examining frequency and severity levels in a college sample. Violence and Victims, 14,365-380.

Foo, L., \& Margolin, G. (1995). A multivariate investigation of dating aggression. Journal of Family Violence, 10, 351-377.

Hendy, H. M., Weiner, K., Bakerofskie, J., Eggen, D., Gustitus, C., \& McLeod, K. C. (2003). Comparison of six models for violent romantic relationships in college men and women. Journal of Interpersonal Violence, 18, 645-665.

Jacobson, N., \& Gottman, J. (1998). When men batter women: New insights into ending abusive relationships. New York: Simon \& Schuster.

Koss, M. P., \& Oros, C. J. (1982). Sexual Experiences Survey: A research instrument investigating sexual aggression and victimization. Journal of Consulting and Clinical Psychology, 50, 455-457. 
Lewis, S. F., \& Fremouw, W. (2000). Dating violence: A critical review of the literature. Clinical Psychology Review, 21, 105-127.

Lewis, S. F., Travea, L., \& Fremouw, W. J. (2002). Characteristics of female perpetrators and victims of dating violence. Violence and Victims, 17, 593-606.

Lloyd, S. A., \& Emery, B. C. (2000). The dark side of courtship: Physical and sexual aggression. Thousand Oaks, CA: Sage.

Lundeberg, K., Stith, S. M., Penn, C. E., \& Ward, D. B. (2004). A comparison of nonviolent, psychologically violent, and physically violent male college daters. Journal of Interpersonal Violence, 19, 1191-1200.

Mahlstedt, D. L., \& Welsh, L. A. (2005). Perceived causes of physical assault in heterosexual dating relationships. Violence Against Women, 11, 447-472.

Makepeace, J. M. (1981). Courtship violence among college students. Family Relations, 30, 97-102.

Makepeace, J. M. (1986). Gender differences in courtship violence victimization. Family Relations, 35, 383-388.

Marcus, R. F., \& Swett, B. (2002). Violence and intimacy in close relationships. Journal of Interpersonal Violence, 17, 570-586.

Mitchell, S. L., \& Lacour, M. M. (2001). Reported interpersonal violence and disposition decisions: The impact of client and counselor variables. Journal of College Counseling, 4, 142-152.

Murphy, C. M., \& Hoover, S. A. (1999). Measuring emotional abuse in dating relationships as a multifactorial construct. Violence and Victims, 14, 39-53.

Neufeld, J., McNamara, J. R., \& Ertl, M. (1999). Incidence and prevalence of dating partner abuse and its relationship to dating practices. Journal of Interpersonal Violence, 14, 125-137.

Nicholson, M. E., Maney, D. W., Blair, K., Wamboldt, P. M., Mahoney, B. S., \& Yuan, J. (1998). Trends in alcohol-related campus violence: Implication for prevention. Journal of Alcohol and Drug Education, 43, 34-52.

Pipes, R. B., \& LeBov-Keeler, K. (1997). Psychological abuse among college women in exclusive heterosexual dating relationships. Sex Roles, 36, 585-603.

Roark, M. L. (1987). Preventing violence on college campuses. Journal of Counseling and Development, 65, 367-371.

Rosen, K. H., \& Bezold, A. (1996). Dating violence prevention: A didactic support group for young women. Journal of Counseling o Development, 74, 521-525.

Schewe, P. A. (2002). Past, present, and future directions for preventing violence in relationships. In P. A. Schewe (Ed.), Preventing violence in relationships: Interventions across the life span (pp. 263-265). Washington, DC: American Psychological Association.

Smith, D. M., \& Donnelly, J. (2001). Adolescent dating violence: A multi-systemic approach of enhancing awareness in educators, parents, and society. Journal of Prevention and Intervention in the Community, 21, 53-64.

Straus, M. A. (2004). Prevalence of violence against dating partners by male and female university students worldwide. Violence Against Women, 10, 790-811.

Straus, M. A., Hamby, S. L., Boney-McCoy, S., \& Sugarman, D. B. (1996). The Revised Conflict Tactics Scales (CTS2): Development and preliminary psychometric data. Journal of Family Issues, 17, 283-316.

Sugarman, D. B., \& Hotaling, G. T. (1989). Dating violence: Prevalence, context, and risk markers. In M. A. Pirog-Good \& J. E. Stets (Eds.), Violence in dating relationships: Emerging social issues (pp. 3-32). New York: Praeger.

Sugarman, D. B., \& Hotaling, G. T. (1997). Intimate violence and social desirability: A metaanalytic review. Journal of Interpersonal Violence, 12, 275-291.

West, A., \& Wandrei, M. L. (2002). Intimate partner violence: A model of predicting interventions by informal helpers. Journal of Interpersonal Violence, 17, 972-986.

White, J. W., \& Koss, M. P. (1991). Courtship violence: Incidence in a national sample of higher education students. Violence and Victims, 6, 247-256. 